\title{
Real-world evaluation of molecular testing and treatment patterns for EGFR mutations in non-small cell lung cancer in Latin America
}

\author{
CLAUDIO MARTIN $^{1}$, MAURICIO CUELLO ${ }^{2}$, OLGA BARAJAS ${ }^{3}$, GONZALO RECONDO $^{4}$, SANDRA ARUACHAN ${ }^{5}$, \\ HERMAN PERROUD ${ }^{6}$, SUSANA SENA ${ }^{7}$, CARLOS BONILLA ${ }^{8}$, FRANCISCO ORLANDI $^{9}$, SUSANA BERUTTI ${ }^{10}$, \\ VIRGINIA GARCIA COCCO ${ }^{11}$, ALVARO GOMEZ ${ }^{12}$, ERNESTO KORBENFELD ${ }^{13}$, MAYCOS ZAPATA $^{14}$, \\ JUAN CUNDOM $^{15}$, ERIC ORELLANA ${ }^{16}$, SUSANA GONCALVES ${ }^{17}$ and FLORENCIA REINHOLD ${ }^{17}$
}

\footnotetext{
${ }^{1}$ Department of Clinical Oncology, Institute Alexander Fleming, Buenos Aires C1426ANZ, Argentina; ${ }^{2}$ Department of Oncology, Hospital of Clinics, Montevideo 11600, Uruguay; ${ }^{3}$ Department of Medical Oncology, Arturo Lopez Perez
} Foundation, Santiago 7500000, Chile; ${ }^{4}$ Department of Thoracic Oncology, Medical education and Clinical Research Centre, University Institute (CEMIC), Buenos Aires C1431FWO, Argentina; ${ }^{5}$ Department of Clinical Oncology,

High Technology Medical Institute Oncomedica, Monteria 23001, Colombia; ${ }^{6}$ Department of Clinical Oncology, Women's Health Centre, Rosario 2000; ${ }^{7}$ Department of Clinical Oncology; German Hospital, Buenos Aires PC C1118AAT, Argentina; ${ }^{8}$ Clinical Oncology Unit, National Cancer Institute of Colombia, Bogotá 110411, Colombia; ${ }^{9}$ Department of Clinical Oncology, Orlandi Oncology, Providencia 7500713, Chile; ${ }^{10}$ Department of Clinical Oncology, Italian Hospital of La Plata, La Plata B1900AXI; ${ }^{11}$ Department of Clinical Oncology, Italian Hospital, Cordoba 5000, Argentina;

${ }^{12}$ Department of Medical Oncology, Hemato-oncologos SA, Cali 760042, Colombia; ${ }^{13}$ Department of Medical Oncology,

British Hospital of Buenos Aires, Buenos Aires C1280AEB, Argentina; ${ }^{14}$ Department of Medical Oncology, Cancer Institute Las Americas, Antioquia 050025, Colombia; ${ }^{15}$ Department of Medical Oncology, Lanari Institute, University of Buenos Aires, Buenos Aires C1427ARN, Argentina; ${ }^{16}$ Department of Clinical Oncology, Clinic Santa Maria, Santiago 7500000, Chile; ${ }^{17}$ AstraZeneca Medical Department, Buenos Aires CP1437, Argentina

Received April 27, 2021; Accepted September 8, 2021

DOI: $10.3892 / \mathrm{mco} .2021 .2439$

\begin{abstract}
Lung cancer is a leading cause of cancer-related deaths in Latin America, with non-small cell lung cancer (NSCLC) being the most prevalent. The current study aimed to report real-world data on epidermal growth factor receptor (EGFR) mutational testing and treatment regimens at diagnosis and progression in patients with metastatic NSCLC across four Latin American countries (Argentina, Chile, Colombia and Uruguay). A retrospective, multicenter,
\end{abstract}

Correspondence to: Dr Martin Claudio, Department of Clinical Oncology, Institute Alexander Fleming, 1180 Crámer, Buenos Aires C1426ANZ, Argentina

E-mail: claudiomartin17@outlook.com

Abbreviations: NSCLC, non-small cell lung cancer; EGFR, epidermal growth factor receptor; TKI, tyrosine kinase inhibitor; PDL-1, programmed death-ligand 1; ALK, anaplastic lymphoma kinase; CNS, central nervous system

Key words: lung cancer, epidermal growth factor receptor, non-small cell lung cancer, Latin America, tyrosine kinase inhibitor observational study was conducted in patients with NSCLC using medical records from participating countries. The study population was categorized into two cohorts: Cohort 1 comprised of newly diagnosed, treatment-naïve patients with stage IV NSCLC; and cohort 2 comprised of stage IV NSCLC EGFR mutation (EGFRm)-positive patients who had progressed after first- or second-generation EGFR-tyrosine kinase inhibitor (TKI) treatment. Measures included demographic variables, health characteristics, treatment regimen, molecular testing rate and turnaround time at diagnosis and at progression for cohorts 1 and 2, respectively. Descriptive statistics were used to summarize all study measures. Of the 462 patients enrolled, 431 were newly diagnosed or treatment naïve with metastatic NSCLC. In cohort 1 , the majority of patients with private health insurance $(57.31 \%)$ underwent molecular diagnosis while only $41.3 \%$ of patients within the public sector had access to testing. The average molecular testing rate in cohort 1 varied across countries, with Argentina having the highest testing rate $(79 \%)$ and Uruguay the lowest (27.63\%). EGFRm was observed in $22 \%$ of patients. Cohort 2 comprised 31 patients who had progressed after first- or second-generation EGFR-TKI treatment and of these, only $22(70.97 \%)$ underwent testing after progression. Access to molecular testing is still a challenge impacting the choice of first-line treatment in Latin American patients with NSCLC. 
These findings underline the unmet needs of ensuring early diagnosis, molecular profiling and use of correct treatment to alleviate NSCLC burden in the region.

\section{Introduction}

Over the last century, lung cancer has advanced as a major global burden and the predominant cause of cancer-related deaths worldwide (1). According to the GLOBOCAN 2018 analysis, lung cancer contributed to $11.6 \%$ of the total diagnosed cancer cases, with a mortality rate of $18.4 \%$ (2). As expected, Latin America shows a similar pattern, with lung cancer being the leading cancer type in the region imposing a major public health issue. Among all cancers, lung cancer mortality ranks number one in Argentina and Uruguay and number two in Chile and Colombia (3).

The most prevalent form of lung cancer accounting for almost $85 \%$ of all lung cancers is non-small cell lung cancer (NSCLC) $(4,5)$. In most cases, lung cancer is diagnosed at advanced or metastatic stage where surgical resection is not amenable and survival is low $(6,7)$. According to a recent Economist Intelligence Unit report, apart from tobacco usage, late detection, and insufficient access to screening and treatment are the leading causes of lung cancer mortality in Latin America (3).

Screening techniques such as low-dose helical computed tomography and broad molecular profiling are key to reducing cancer-based mortality (8-10). The implementation of these techniques require well-structured diagnostic approaches and good public health systems. Platinum-based therapy has been the standard of care in advanced NSCLC. However, the discovery of new molecular alterations and development of respective targeted treatments represent a major improvement over conventional chemotherapy when applied to appropriately selected patient populations. Testing of mutation specific to epidermal growth factor receptor $(E G F R)$ and $B R A F$ $V 600 E$, rearrangement of ROS1 genes (c-ros oncogene 1) and ALK (anaplastic lymphoma kinase) as well as alteration in programmed death-ligand 1 (PDL-1) expression are critical factors for advanced or metastatic NSCLC treatment strategy. Currently, targeted therapies and checkpoint inhibitors are being widely approved for these specific genetic aberrations. Furthermore, mutations in genes like MET exon 14 and HER2 (human epidermal growth factor receptor 2) and fusion genes involving RET (rearranged during transfection) and NTRK1 (neurotropic tropomyosin receptor kinase 1) are also evolving as important targets or biomarkers (11).

Apart from high mortality rates, lung cancer in Latin America is also associated with high direct and indirect costs $(3,12)$. Although the Latin American countries have national treatment guidelines, real-world data on molecular testing and treatment pattern are limited (3). A lack of data on existing practices hinders identification of the actual requirements and effective economic management.

The current study presents real-world data on the management of patients with stage IV NSCLC in four Latin American countries including Argentina, Colombia, Chile, and Uruguay. This retrospective study aimed to evaluate the molecular testing and treatment patterns in a cohort of newly diagnosed, treatment-naïve patients with advanced or metastatic NSCLC and in another cohort of EGFR mutation-positive patients who had progressed after EGFR-tyrosine kinase inhibitor (TKI) treatment.

\section{Materials and methods}

Study design. This retrospective, multicenter study was conducted in patients with stage IV NSCLC from the four Latin American countries including Argentina, Colombia, Chile, and Uruguay diagnosed from January 1, 2017 to December 31, 2017. All data were collected using patient medical records and transferred from patients' medical record book to a secure web-based electronic case report form by the physician or trained study personnel in accordance with outlined data entry procedures.

The study was performed in accordance with ethical principles that are consistent with the Declaration of Helsinki, International Conference on Harmonization-Good Clinical Practice (ICH GCPs), and the applicable legislation. The final study protocol was approved in writing by the Ethics Committee (EC) for each site in all the countries that participated.

Study population. The study population was categorized into two cohorts: cohort 1 comprised newly diagnosed and treatment-naïve patients aged $\geq 18$ years with stage IV NSCLC; cohort 2 comprised stage IV NSCLC EGFR mutation-positive patients who had progressed after first- or second-generation EGFR-TKI treatment.

Furthermore, all included patients were required to provide written informed consent as per local regulations. There were no minimum reporting requirements for the medical record to be eligible other than those specified for each cohort. Data were collected post diagnosis of advanced or metastatic NSCLC in cohort 1 and post EGFR-TKI progression in cohort 2 up to maximum follow-up registered in the medical record book.

Measures. The demographic variables examined in the study included age, gender, smoking status, and health insurance status for both cohorts. The health characteristics reported include ECOG and histology type. Molecular testing rate, biopsy site, and turnaround time at diagnosis for cohort 1 and at progression for cohort 2 were reported. Molecular profiling including EGFR mutations and subsequent treatment strategies were followed for both cohorts.

Statistical analysis. No formal hypothesis testing was incorporated in the study. Descriptive statistics (mean, standard deviations for continuous variables and frequencies and percentages for categorical variables) was used to summarize all study measures.

\section{Results}

Demographic and clinical characteristics in the treatment-naïve cohort. Of the 462 patients enrolled in the present study, 431 (93.2\%) were newly diagnosed or treatment naïve with advanced or metastatic NSCLC from Argentina $(n=195)$, Colombia $(n=96)$, Chile $(n=64)$, and Uruguay $(n=76)$. The mean age of patients in cohort 1 was $66 \pm 11$ years; 
$60 \%$ of the patients were men and $57.3 \%$ had private insurance coverage. Among all the study nations, Argentina had the highest private insurance coverage (87\%) and Uruguay reported the lowest private insurance coverage (8\%).

Most of the patients with NSCLC were found to either have a smoking history (41\%) or were active smokers (37\%), whereas a small proportion of patients $(16.4 \%)$ had no smoking history. The highest percentage of current smokers among the four nations was observed in Uruguay (62\%), followed by Argentina (39\%) and Chile (28\%) (Table I). The majority of patients in cohort $1(71.0 \%)$ had adenocarcinoma histology. The metastatic sites reported were highest in bone (41.8\%), followed by lymph nodes (36.7\%), brain $(20.4 \%)$, adrenal (13.7\%), and liver (14.3\%). Tumor characteristics were similar in almost all the countries, including high rates of bone metastasis and adenocarcinoma histology, except in Uruguay which had lower rates of adenocarcinoma.

Among all patients diagnosed in stage IV, Performance Status (PS) of almost half (48\%) showed PS $0-1 ; 14 \%$ of the patients were PS 2 , whereas only $7.7 \%$ of the patients were severely or completely disabled (PS 3 or 4). Most patients were diagnosed in advanced or metastatic stages (stage III: 9\%; stage IV: $76 \%$ ) and only $5 \%$ were diagnosed at early stages (I-II).

Molecular testing. On an average, the frequency of molecular testing was $66 \%$, with Argentina having the highest testing rate $(79 \%)$ with a population belonging primarily to the private sector $(87 \%)$ and Uruguay having the lowest testing rate $(28 \%)$ but with a population belonging primarily to the public sector $(91 \%)$. The mean turnaround time for testing was 12.4 days, with Colombia reporting the longest turnaround time (Argentina, 10; Colombia, 20.4; Chile, 10; Uruguay, 13.4). Formalin fixed paraffin embedded tissue was commonly used for sample processing and further testing (55.68\%; Argentina, 68.72\%; Colombia, 46\%; Chile, 64\%; Uruguay, 27.6\%). The percentage of samples collected as blood (2.3\%), fresh frozen tissue $(1.1 \%)$, or cytology $(0.46 \%)$ was relatively less. Unknown sample collection procedures accounted for $40.1 \%$ of the patients. PDL-1 testing was performed in the majority of patients $(89.1 \%)$ (Table II).

Molecular profile and treatment patterns. Among all the patients, the frequency of EGFR mutations in NSCLC was 22.2\% (Argentina, 26\%; Colombia, 26\%; Chile, $8.3 \%$; Uruguay, $19.0 \%$ ). The most frequent EGFR mutation was exon 19 deletion (47\%), followed by exon 21 L858R (36\%). The frequency of ALK mutation in the tested population was $2.4 \%$, followed by KRAS (1.4\%), MET (1.4\%), and ROS1 (1.04\%) (Table III).

Chemotherapy was the most common first-line treatment (51\%), specifically platinum-based chemotherapy (Table SI) followed by targeted therapy (12.5\%) and immunotherapy (3.7\%). Immunotherapy was mainly based on immune check point inhibitors (Table SII). Unknown first-line treatment procedures or untreated patients accounted for $32.9 \%$.

Demographic and clinical characteristics of the progressed NSCLC cohort. A total of 31 patients from Argentina $(\mathrm{n}=25$, Colombia $(n=5)$, and Chile $(n=1)$ with stage IV NSCLC who had progressed after first- or second-generation EGFR-TKI treatment were included in cohort 2 . The majority of these patients were female (77.4\%), with a mean age of $58 \pm 12$ years; all of them had adenocarcinoma histology with private health insurance (77.4\%) and no smoking history (64.5\%) (Table IV).

Gefitinib was the most common previous TKI (41.9\%) used, followed by afatinib (35.48\%) and erlotinib (22.58\%). The most frequent tumor metastasis was observed in the bone (32.3\%), followed by brain (16.13\%), lymph nodes (16.13\%), liver (16.13\%), and adrenal gland(s) (9.68\%). Approximately $19.35 \%$ of patients with targeted therapy showed no restricted disability ( $P S=0$ ), whereas $22.58 \%$ showed limited physical disability ( $\mathrm{PS}=1$ ).

In cohort 2, 71\% of patients underwent a post-progression diagnostic test. The reasons for not testing included physicians' decision and severity of disease. Thorax was the most common site of progression observed in majority of the patients (61.3\%), followed by lymph nodes (19.4\%) and sinonasal cancer (SNC) (19.4\%). The most frequent biopsy method used at progression was Circulating Tumor DNA (ctDNA) (63.6\%) (Table V).

Molecular profile and treatment at progression. Half of the tested patients were found to be T790M positive. Ten (32\%) patients received osimertinib in the second line, whereas another $5(16 \%)$ received it as third-line treatment. Patients who did not progress with T790M mainly received chemotherapy and less frequently immunotherapy in the second or third line (Table VI).

\section{Discussion}

Lung cancer is the main cause of cancer-related deaths in Latin America (13). Data scarcity on lung cancer related to clinical practices impedes progress in eliminating the disease burden. Thus, real-word data are becoming increasingly important in the clinical care of cancer patients. This retrospective real-world study evaluated the current situation of lung cancer diagnosis including molecular testing patterns and treatment regimens followed for the management of NSCLC in Argentina, Colombia, Chile, and Uruguay. The study focused on two cohorts: newly diagnosed stage IV NSCLC patients and patients with EGFR mutations who had progressed after EGFR-TKI therapy.

Of the 431 patients included in the treatment-naïve cohort, almost $90 \%$ were diagnosed at advanced stages and only $8 \%$ were diagnosed at early stages. Although the study data do not allow conclusions to be drawn because of the characteristics of the inclusion criteria, early diagnosis is still an unmet need in Latin America (13). The reasons for this include low threshold for respiratory symptoms, especially among heavy smokers; delayed consultation; and lack of programs for lung cancer screening in the region.

Despite international guidelines emphasizing the importance of molecular testing, poor access to testing has been widely reported in Latin America (14). Although two-third of the treatment-naïve cohort underwent molecular testing, this study observed disparity in testing rates among countries, from as low as 28\% in Uruguay to almost $79 \%$ in Argentina. The differences between the testing of genetic mutations and the search for tumor biomarkers (66\% for genetic alterations vs. $89 \%$ for PDL-1 testing) are also evident, even though the 
Table I. Demographics and clinical characteristics of the newly diagnosed treatment-naïve cohort.

\begin{tabular}{|c|c|c|c|c|c|}
\hline Characteristics & Argentina $(n=195)$ & Colombia $(n=96)$ & Chile $(n=64)$ & Uruguay $(n=76)$ & Total $(n=431)$ \\
\hline Age, mean \pm SD & $66 \pm 11.00$ & $67 \pm 10.50$ & $67 \pm 8.96$ & $66 \pm 9.92$ & $66 \pm 11.00$ \\
\hline \multicolumn{6}{|l|}{ Sex, n (\%) } \\
\hline Male & $105(53.8)$ & $62(64.6)$ & $34(63.5)$ & $56(73.7)$ & $257(59.6)$ \\
\hline Female & $90(46.1)$ & $34(35.4)$ & 30 (46.9) & $20(26.3)$ & $174(40.4)$ \\
\hline \multicolumn{6}{|c|}{ Health insurance status, n (\%) } \\
\hline Private & $169(86.7)$ & $49(51.0)$ & $23(35.9)$ & $6(7.9)$ & $247(57.3)$ \\
\hline Public & $25(12.8)$ & $44(45.8)$ & $41(64.1)$ & $69(90.8)$ & $179(41.5)$ \\
\hline Unknown & $0(0.0)$ & $3(3.1)$ & $0(0.0)$ & $1(1.3)$ & $5(1.7)$ \\
\hline \multicolumn{6}{|l|}{ Smoking status, $\mathrm{n}(\%)$} \\
\hline Current & $76(39.0)$ & $19(19.8)$ & $18(28.1)$ & $47(61.8)$ & $160(37.1)$ \\
\hline Former & $73(37.4)$ & $55(57.3)$ & $27(42.2)$ & $21(27.6)$ & $176(40.8)$ \\
\hline Never & $35(17.9)$ & $17(17.7)$ & $13(20.3)$ & $6(7.9)$ & $71(16.5)$ \\
\hline Unknown & $11(5.6)$ & $5(5.2)$ & $6(9.4)$ & $2(2.6)$ & $24(5.8)$ \\
\hline \multicolumn{6}{|c|}{ Family history of lung cancer, n (\%) } \\
\hline Yes & $19(9.7)$ & $3(3.1)$ & $4(6.2)$ & $3(3.9)$ & $29(6.7)$ \\
\hline No & $113(57.9)$ & $66(68.7)$ & $23(35.9)$ & $36(47.4)$ & $238(55.2)$ \\
\hline Unknown & $63(32.3)$ & $25(26.0)$ & $37(57.8)$ & $37(48.7)$ & $164(38.0)$ \\
\hline \multicolumn{6}{|l|}{ Histology type, n (\%) } \\
\hline Adenocarcinoma & $155(79.5)$ & $71(74.0)$ & $51(79.7)$ & $30(39.5)$ & $307(71.1)$ \\
\hline Squamous cell & $22(11.3)$ & $15(15.6)$ & $8(12.5)$ & $14(18.4)$ & $59(13.7)$ \\
\hline Others or unknown & $18(9.2)$ & $10(10.4)$ & $5(7.8)$ & $32(42.1)$ & $65(15.1)$ \\
\hline \multicolumn{6}{|c|}{ Stage at original diagnosis, $\mathrm{n}(\%)$} \\
\hline IA & $5(2.6)$ & $0(0.0)$ & $0(0.0)$ & $0(0.0)$ & $5(1.7)$ \\
\hline IB & $7(3.6)$ & $0(0.0)$ & $0(0.0)$ & $0(0.0)$ & $7(1.6)$ \\
\hline IIA & $1(0.5)$ & $2(2.1)$ & $0(0.0)$ & $2(2.63)$ & $6(1.4)$ \\
\hline IIB & $4(2.0)$ & $0(0.0)$ & $0(0.0)$ & $0(0.0)$ & $4(0.9)$ \\
\hline IIIA & $10(5.1)$ & $2(2.1)$ & $0(0.0)$ & $1(1.3)$ & $13(3.0)$ \\
\hline IIIB & $14(7.2)$ & $4(4.2)$ & $1(1.6)$ & $0(0.0)$ & $18(4.2)$ \\
\hline IIIC & $1(0.5)$ & $0(0.0)$ & $1(1.6)$ & $3(3.95)$ & $5(1.2)$ \\
\hline IVA & $45(23.1)$ & $33(34.4)$ & $22(34.4)$ & $12(15.8)$ & $112(26.0)$ \\
\hline IVB & $108(55.4)$ & $55(57.3)$ & $40(62.5)$ & $58(76.3)$ & $261(60.6)$ \\
\hline \multicolumn{6}{|l|}{$\begin{array}{l}\text { Site of metastasis at } \\
\text { diagnosis, } \mathrm{n}(\%)\end{array}$} \\
\hline Brain/CNS & $36(18.5)$ & 17 (17.7) & $17(26.6)$ & $18(23.8)$ & $88(20.4)$ \\
\hline Bone & $84(43.1)$ & $37(38.5)$ & $28(43.7)$ & $31(40.8)$ & $180(41.8)$ \\
\hline Lymph node & $71(36.1)$ & $27(28.1)$ & $27(42.2)$ & $33(43.4)$ & $158(36.7)$ \\
\hline Adrenal & $26(13.3)$ & $11(11.5)$ & $8(12.5)$ & $14(18.4)$ & $59(13.7)$ \\
\hline Liver & $20(10.3)$ & $9(9.4)$ & $13(20.3)$ & $20(26.3)$ & $62(14.4)$ \\
\hline \multicolumn{6}{|l|}{ ECOG PS, n (\%) } \\
\hline 0 & $41(21.0)$ & $16(16.7)$ & $13(20.3)$ & $12(15.8)$ & $82(19.0)$ \\
\hline 1 & $52(26.7)$ & $33(34.4)$ & $24(37.5)$ & $17(22.4)$ & $126(29.2)$ \\
\hline 2 & $25(12.8)$ & $18(18.7)$ & $6(9.4)$ & $13(17.1)$ & $62(14.4)$ \\
\hline 3 & $10(5.1)$ & $4(4.2)$ & $0(0.0)$ & $12(15.8)$ & $26(6.0)$ \\
\hline 4 & $3(1.5)$ & $1(1.0)$ & $00(0.0)$ & $3(3.9)$ & 7 (1.6) \\
\hline Unknown & $64(32.8)$ & $24(25.0)$ & $21(32.8)$ & $19(25.0)$ & $128(29.7)$ \\
\hline
\end{tabular}

ECOG scores are divided as follows: 0 , fully active, able to carry out all pre-disease performance without restriction; 1 , restricted in physically strenuous activity, but ambulatory and able to carry out work of a light or sedentary nature (for example, light housework and office work); 2 , ambulatory and capable of all self-care but unable to carry out any work activities (up and active for $>50 \%$ of waking hours); 3 , capable of only limited self-care, confined to bed or chair for $>50 \%$ of waking hours. CNS, central nervous system; ECOG, Eastern Cooperative Oncology Group; PS, performance status. 
Table II. Molecular testing frequency for the treatment-naïve cohort.

\begin{tabular}{|c|c|c|c|c|c|}
\hline Parameter & Argentina $(n=195)$ & Columbia $(\mathrm{n}=96)$ & Chile $(n=64)$ & Uruguay (n=76) & Total $(n=431)$ \\
\hline Testing rate, $\%$ & 78.8 & 64.6 & 75.0 & 27.6 & 65.7 \\
\hline PDL-1 testing rate, $\%$ & 91.2 & 87.5 & 75.0 & 98.7 & 89.1 \\
\hline Turnaround time in days, mean & 9.9 & 20.4 & 10.0 & 13.5 & 12.4 \\
\hline Blood (plasma/serum) & $4(2.0)$ & $6(6.2)$ & $0(0.0)$ & $0(0.0)$ & $10(2.3)$ \\
\hline Cytology & $0(0.0)$ & $2(2.1)$ & $0(0.0)$ & $0(0.0)$ & $2(0.5)$ \\
\hline $\begin{array}{l}\text { Formalin fixed paraffin } \\
\text { embedded tissue }\end{array}$ & $134(68.7)$ & $44(45.8)$ & $41(64.1)$ & $21(27.6)$ & $240(55.7)$ \\
\hline Fresh frozen tissue & $4(2.0)$ & $0(0.0)$ & $1(1.6)$ & $0(0.0)$ & $5(1.2)$ \\
\hline Unknown/no treatment, n (\%) & $52(26.8)$ & $44(45.8)$ & $22(34.4)$ & $55(72.4)$ & $173(40.1)$ \\
\hline
\end{tabular}

PDL-1, programmed death-ligand 1.

search for oncogenic drivers and the consequent targeted therapy have been shown to increase patient survival and should therefore be the first diagnostic approach to treatment choice (15).

The frequency of EGFR mutations (22\%) observed in our study is comparable with other Latin American studies that reported $26 \%$ in patients with NSCLC (16). Despite these limitations, the mean turnaround time for testing was consistent with that recommended by international guidelines (17). While treatment for advanced stages of the disease is moving toward immuno-oncology therapy (monotherapy or combined with chemotherapy) and targeted therapies in the majority of countries, first-line treatment in the Latin American region is still based on chemotherapy and target agents. In this study, the most commonly used first-line treatment for newly diagnosed patients with stage IV NSCLC was platinum-based chemotherapy, followed by target agents and immunotherapy. However, as a second-line of treatment strategy, immunotherapy was the preferred choice, followed by chemotherapy and target agents.

Since 2013, clinical guidelines have strongly recommended repeated molecular testing upon progression on first- and second-generation EGFR-TKIs to detect mutations such as T790M (17). Third-generation TKI osimertinib has led to a paradigm shift in the management of patients with metastatic NSCLC who develop T790M resistance mutation. The need for tumor genotyping is thus highly supported at the time of diagnosis and at disease progression (18). In previous studies among patients with NSCLC who had progressed after first-line EGFR-TKI therapy, approximately $60 \%$ were T790M positive $(19,20)$. Our study shows a comparable proportion of T790M-positive patients $(59 \%)$. However, the small sample size for patients who showed disease progression in this cohort might cause bias for this result and should be interpreted cautiously.

For molecular genotyping at progression, either tissue $(36 \%)$ or blood $(63.6 \%)$ sample was used for EGFR testing. The possible reason for blood samples being commonly used could be the ease of sample collection and the difficulty in obtaining tissue in some patients with disease progression. Both techniques have shown correlation in mutation assessment, irrespective of the biopsy method used $(21,22)$. Nevertheless, not all patients in this study who received first- or second-generation EGFR-TKIs and progressed were tested for T790M prior to initiating subsequent therapy. Of the 31 patients with NSCLC who showed progression after treatment, only 22 (71\%) were tested, and among these, 13 had a positive resistance mutation T790M, which was found either alone or in combination with baseline sensitizing mutation, and received osimertinib. In addition, two patients received osimertinib without confirmation of T790M at progression because of central nervous system (CNS) compromise based on preclinical and clinical activity shown in patients with CNS metastases (4). Of note, at the time of this study, osimertinib was approved in Argentina, Colombia, and Chile but not in Uruguay for second-line treatment with T790M resistance mutation. The most common second- or third-line treatment for patients without T790M mutation was chemotherapy, followed by a very limited use of immunotherapy because of the poor activity of these agents in oncogene-driven NSCLC (23).

Approximately $30 \%$ of the patients who had progressed after EGFR-TKI treatment could not be re-biopsied and, of those tested, $42 \%$ progressed with T790M. This study highlights the importance of choosing the most optimal treatment option for patients with EGFR-mutated NSCLC in the first-line setting.

Strengths and limitations. The study sheds light on real-world practices with respect to lung cancer diagnosis and management in Latin America. The data are collected from medical records and closely resemble present clinical practices in the four study countries. It is important, however, to consider the implications of these results in line with the study limitations.

The sample size varies among the study countries, which could introduce bias. The results of this study among patients who showed progression should be interpreted cautiously considering the small sample size. The retrospective nature of the study could also reflect recall biases and other forms of measurement. Furthermore, given the cross-sectional design of the study, statements of causality cannot be made from the 
Table III. EGFR mutation frequency, molecular profile and treatment patterns of the treatment-naïve cohort.

\begin{tabular}{|c|c|c|c|c|c|}
\hline Parameter & Argentina $(n=195)$ & Columbia $(n=96)$ & Chile $(n=64)$ & Uruguay $(\mathrm{n}=76)$ & Total $(n=431)$ \\
\hline Tested population, $\mathrm{n}$ & 154 & 62 & 48 & 21 & 288 \\
\hline \multicolumn{6}{|l|}{ EGFR mutations, n (\%) } \\
\hline Exon 18 & $3(1.9)$ & $1(1.6)$ & $1(2.1)$ & $0(0.0)$ & $5(1.2)$ \\
\hline Exon 19 deletion & $17(11.0)$ & $10(16.1)$ & $2(4.2)$ & $1(4.8)$ & $30(10.4)$ \\
\hline Exon 20 insertion & $1(0.5)$ & $1(1.6)$ & $0(0.0)$ & $0(0.0)$ & $2(0.7)$ \\
\hline T790M de novo & $1(0.6)$ & $0(0.0)$ & $0(0.0)$ & $0(0.0)$ & $1(0.3)$ \\
\hline Other & $1(0.6)$ & $0(0.0)$ & $0(0.0)$ & $0(0.0)$ & $1(0.3)$ \\
\hline Exon $21 \mathrm{~L} 858 \mathrm{R}$ & $15(9.7)$ & $4(6.4)$ & $1(2.1)$ & $3(14.3)$ & $23(8.0)$ \\
\hline Other & $2(1.3)$ & $0(0.0)$ & $0(0.0)$ & $0(0.0)$ & $2(0.7)$ \\
\hline Total EGFR mutations, n (\%) & $40(26.0)$ & $16(25.8)$ & $4(8.3)$ & $4(19.0)$ & $64(22.2)$ \\
\hline ALK, n (\%) & $4(2.0)$ & $1(1.0)$ & $1(1.6)$ & $1(4.8)$ & $7(2.4)$ \\
\hline ROS1, n (\%) & $3(1.5)$ & $0(0.0)$ & $0(0.0)$ & $0(0.0)$ & $3(1.0)$ \\
\hline KRAS, n (\%) & $4(2.0)$ & $0(0.0)$ & $0(0.0)$ & $0(0.0)$ & $4(1.4)$ \\
\hline MET, n (\%) & $4(2.0)$ & $0(0.0)$ & $0(0.0)$ & $0(0.0)$ & $4(1.4)$ \\
\hline \multicolumn{6}{|l|}{ Treatment pattern, n (\%) } \\
\hline \multicolumn{6}{|l|}{ Chemotherapy } \\
\hline First line & $107(54.9)$ & $41(42.7)$ & $41(64.1)$ & $31(40.8)$ & $219(51.0)$ \\
\hline Second line & $14(7.2)$ & $6(6.3)$ & $6(9.4)$ & $3(3.9)$ & $24(5.6)$ \\
\hline Third line & $0(0.0)$ & $0(0.0)$ & $0(0.0)$ & $3(3.9)$ & $3(0.7)$ \\
\hline Systemic therapy, n (\%) & $152(77.9)$ & $60(62.5)$ & $53(82.8)$ & $36(47.4)$ & $301(69.8)$ \\
\hline \multicolumn{6}{|l|}{$\begin{array}{l}\text { Targeted EGFR-TKI } \\
\text { therapy, } \mathrm{n}(\%)\end{array}$} \\
\hline First line & $24(12.3)$ & $13(13.5)$ & $4(6.3)$ & $3(3.9)$ & $44(10.2)$ \\
\hline Second line & $11(5.6)$ & $3(3.1)$ & $1(1.6)$ & $0(0.0)$ & $15(3.5)$ \\
\hline Third line & $1(0.5)$ & $0(0.0)$ & $0(0.0)$ & $0(0.0)$ & $1(0.2)$ \\
\hline \multicolumn{6}{|l|}{$\begin{array}{l}\text { Targeted therapy, ALK/ROS1 } \\
\text { inhibitors }\end{array}$} \\
\hline First line & $6(3.1)$ & $2(2.1)$ & $2(3.4)$ & $0(0.0)$ & $10(2.3)$ \\
\hline Second line & $1(0.5)$ & $0(0.0)$ & $0(0.0)$ & $0(0.0)$ & $1(0.2)$ \\
\hline Third line & $0(0.0)$ & $0(0.0)$ & $0(0.0)$ & $0(0.0)$ & $0(0.0)$ \\
\hline \multicolumn{6}{|l|}{ Immunotherapy, n (\%) } \\
\hline First line & $12(6.2)$ & $1(1.0)$ & $3(4.7)$ & $0(0.00)$ & $16(3.7)$ \\
\hline Second line & $16(8.2)$ & $3(3.1)$ & $7(10.9)$ & $5(6.6)$ & $29(6.7)$ \\
\hline Third line & $3(1.5)$ & $0(0.0)$ & $0(0.0)$ & $0(0.0)$ & $3(0.7)$ \\
\hline Surgeries, n (\%) & $23(11.8)$ & $12(12.5)$ & $6(9.4)$ & $3(3.9)$ & $44(10.2)$ \\
\hline Radiotherapy, n (\%) & $60(30.7)$ & $29(30.2)$ & $22(34.4)$ & $35(46.0)$ & $146(33.9)$ \\
\hline \multicolumn{6}{|c|}{ Treatment for CNS metastasis, n (\%) } \\
\hline Whole brain radiotherapy & $19(9.7)$ & $12(12.5)$ & $8(12.5)$ & $11(14.5)$ & $50(11.6)$ \\
\hline Brain surgery & $6(3.1)$ & $3(3.1)$ & $1(1.6)$ & $4(5.3)$ & $14(3.2)$ \\
\hline Stereotactic radiosurgery & $6(3.1)$ & $1(1.0)$ & $2(3.13)$ & $0(0)$ & $9(2.1)$ \\
\hline \multicolumn{6}{|l|}{ Unknown/no treatment, $\mathrm{n}(\%)$} \\
\hline First line & $46(23.6)$ & $39(40.6)$ & $14(21.9)$ & $42(55.3)$ & $142(32.9)$ \\
\hline Second line & $153(78.5)$ & $84(87.5)$ & $50(78.1)$ & $68(89.5)$ & $360(83.5)$ \\
\hline Third line & $191(97.9)$ & $96(100.0)$ & $64(100.0)$ & $73(96.1)$ & $425(98.6)$ \\
\hline
\end{tabular}

First-line chemotherapy regimens include platinum duplets $(96 \%)$, platinum duplets plus bevacizumab (3\%) or monotherapies $(2 \%)$. Second-line chemotherapy includes platinum duplets for patients receiving immune oncology or target agents in the first line; docetaxel and maintenance regimens (pemetrexed). Immunotherapy refers to either pembrolizumab, nivolumab, nivolumab + ipilimumab or atezolizumab ALK/inhibitors, anaplastic lymphoma kinase inhibitors. CNS, central nervous system; EGFR, epidermal growth factor receptor; KRAS, Kirsten rat sarcoma viral oncogene homolog; MET, mesenchymal-epithelial transition; ROS1, reactive oxygen species inhibitors; TKI, tyrosine kinase inhibitor. 
Table IV. Demographics and clinical characteristics of the cohort with non-small cell colorectal cancer progression.

\begin{tabular}{|c|c|c|c|c|}
\hline Characteristic & Argentina $(n=25)$ & Colombia $(n=5)$ & Chile $(n=1)$ & Total $(n=31)$ \\
\hline Age, mean \pm SD & $56.84 \pm 12.49$ & $63.8 \pm 8.40$ & 68.00 (NA) & $58.32 \pm 12.01$ \\
\hline \multicolumn{5}{|l|}{ Sex, n (\%) } \\
\hline Female & $18(72.0)$ & $5(100.0)$ & $1(100.0)$ & $24(77.4)$ \\
\hline Male & $7(28.0)$ & $0(0.0)$ & $0(0.0)$ & $7(22.6)$ \\
\hline \multicolumn{5}{|c|}{ Health insurance status, $\mathrm{n}(\%)$} \\
\hline Private & $22(88.0)$ & $2(40.0)$ & $0(0.0)$ & $24(77.4)$ \\
\hline Public & $1(4.0)$ & $3(60.0)$ & $1(100.0)$ & $5(16.1)$ \\
\hline Unknown & $2(8.0)$ & $0(0.0)$ & $0(0.0)$ & $2(6.4)$ \\
\hline \multicolumn{5}{|l|}{ Smoking status, n (\%) } \\
\hline Current & $2(8.0)$ & $0(0.0)$ & $1(100.0)$ & $3(9.7)$ \\
\hline Former & $3(12.0)$ & $1(20.0)$ & $0(0.0)$ & $4(12.9)$ \\
\hline Never & $17(68.0)$ & $3(60.0)$ & $0(0.0)$ & $20(64.5)$ \\
\hline Unknown & $3(12.0)$ & $1(20.0)$ & $0(0.0)$ & $4(12.9)$ \\
\hline \multicolumn{5}{|c|}{ Family history of cancer, n (\%) } \\
\hline Yes & $0(0.0)$ & $1(20.0)$ & $0(0.0)$ & $1(3.2)$ \\
\hline No & $18(72.0)$ & $3(60.0)$ & $0(0.0)$ & $21(67.7)$ \\
\hline Unknown & $7(28.0)$ & $1(20.0)$ & $1(100.0)$ & $9(29.0)$ \\
\hline Previous TKI, n (\%) & $25(100.0)$ & $5(100.0)$ & $1(100.0)$ & $31(100.0)$ \\
\hline Afatinib & $11(44.0)$ & $0(0.0)$ & $0(0.0)$ & $11(35.5)$ \\
\hline Erlotinib & $5(20.0)$ & $2(40.0)$ & $0(0.0)$ & $7(22.6)$ \\
\hline Gefitinib & $9(36.0)$ & $3(60.0)$ & $1(100.0)$ & $13(41.9)$ \\
\hline \multicolumn{5}{|l|}{ Histology type, n (\%) } \\
\hline Adenocarcinoma & $25(100.0)$ & $5(100.0)$ & $1(100.0)$ & $31(100.0)$ \\
\hline Squamous cell & $0(0.0)$ & $0(0.0)$ & $0(0.0)$ & $0(0.0)$ \\
\hline Other or unknown & $0(0.0)$ & $0(0.0)$ & $0(0.0)$ & $0(0.0)$ \\
\hline \multicolumn{5}{|c|}{ Site of metastasis at progression $\mathrm{n}(\%)$} \\
\hline Brain/CNS & $4(16.0)$ & $1(20.0)$ & $0(0.0)$ & $5(16.1)$ \\
\hline Bone & $7(28.0)$ & $3(60.0)$ & $0(0.0)$ & $10(32.3)$ \\
\hline Lymph node & $5(20.0)$ & $0(0.0)$ & $0(0.0)$ & $5(16.1)$ \\
\hline Adrenal & $2(8.0)$ & $1(20.0)$ & $0(0.0)$ & $3(9.7)$ \\
\hline Liver & $4(16.0)$ & $1(20.0)$ & $0(0.0)$ & $5(16.1)$ \\
\hline \multicolumn{5}{|l|}{ ECOG, n (\%) } \\
\hline 0 & $6(24.0)$ & $0(0.0)$ & $0(0.0)$ & $6(19.3)$ \\
\hline 1 & $4(16.0)$ & $3(60.0)$ & $0(0.0)$ & $7(22.6)$ \\
\hline 2 & $3(12.0)$ & $1(20.0)$ & $0(0.0)$ & $4(12.9)$ \\
\hline 3 & $0(0.0)$ & $0(0.0)$ & $0(0.0)$ & $0(0.0)$ \\
\hline 4 & $1(4.0)$ & $0(0.0)$ & $0(0.0)$ & $1(3.2)$ \\
\hline Unknown & $11(44.0)$ & $1(20.0)$ & $1(100.0)$ & $12(38.7)$ \\
\hline
\end{tabular}

ECOG scores were as follows: 0, fully active, able to carry out all pre-disease performance without restriction; 1 , restricted in physically strenuous activity, but ambulatory and able to carry out work of a light or sedentary nature (for example light housework and office work); 2 , ambulatory and capable of self-care but unable to carry out any work activities (up and active for $>50 \%$ of waking hours); 3 , capable of only limited self-care, confined to bed or chair for $>50 \%$ of waking hours. CNS, central nervous system; ECOG, Eastern Cooperative Oncology Group; TKI, tyrosine kinase inhibitor.

results, and temporal trends in the relationships between study variables cannot be ascertained. Limitations in data analysis arise as a result of the finite set of measured variables and there is the possibility that unmeasured variables may have an impact on these outcomes.
This real-world study provides insight into diagnosis, mutation testing, and treatment patterns in patients with metastatic NSCLC at diagnosis as well as in patients who had progressed after EGFR-TKI treatment in four Latin American countries. The molecular profile testing rate at stage IV NSCLC is low. 
Table V. Post-progression test frequency and characteristics of the cohort with non-small cell lung cancer progression.

\begin{tabular}{|c|c|c|c|c|}
\hline Parameter & Argentina $(n=25)$ & Colombia $(\mathrm{n}=5)$ & Chile $(\mathrm{n}=1)$ & Total $(\mathrm{n}=31)$ \\
\hline \multicolumn{5}{|c|}{ Post-progression diagnostic test, $\mathrm{n}(\%)$} \\
\hline Yes & $19(76.0)$ & $3(60.0)$ & $0(0.0)$ & $22(71.0)$ \\
\hline No & $5(20.0)$ & $2(40.0)$ & $1(100.0)$ & $8(25.8)$ \\
\hline Unknown & $1(4.0)$ & $0(0.0)$ & $0(0.0)$ & $1(3.2)$ \\
\hline \multicolumn{5}{|c|}{ Biopsy method at progression, $\mathrm{n}(\%)$} \\
\hline Primary tumor & $3(12.0)$ & $1(20.0)$ & $0(0.0)$ & $4(18.2)$ \\
\hline Metastasis site & $3(12.0)$ & $1(20.0)$ & $0(0.0)$ & $4(18.2)$ \\
\hline ctDNA (liquid biopsy) & $13(52.0)$ & $1(20.0)$ & $0(0.0)$ & $14(63.6)$ \\
\hline \multicolumn{5}{|l|}{ Site of progression, $\mathrm{n}(\%)$} \\
\hline Within the thorax & $15(60.0)$ & $3(60.0)$ & $1(100.0)$ & $19(61.3)$ \\
\hline Lymph nodes & $6(24.0)$ & $0(0.0)$ & $0(0.0)$ & $6(19.3)$ \\
\hline $\mathrm{SNC}$ & $4(16.0)$ & $2(40.0)$ & $0(0.0)$ & $6(19.3)$ \\
\hline Bone and liver & $8(32.0)$ & $3(60.0)$ & $0(0.0)$ & $11(35.5)$ \\
\hline
\end{tabular}

ctDNA, circulating tumor DNA; SNC, sinonasal cancer.

Table VI. Epidermal growth factor receptor mutation frequency, molecular profile and treatment patterns in the cohort with non-small cell colorectal cancer progression.

\begin{tabular}{lc}
\hline Parameter & Total $(\mathrm{n}=31)$ \\
\hline Tested population, $\mathrm{n}(\%)$ & $22(71.0)$ \\
T790M mutations, $\mathrm{n}$ & 2 \\
T790M + exon 19 deletion, $\mathrm{n}$ & 7 \\
T790M+ L858R, $\mathrm{n}$ & 4 \\
Total T790M mutations, $\mathrm{n}$ & 13 \\
Treatment at progression, $\mathrm{n}$ & \\
Chemotherapy & 5 \\
Second line & 4 \\
Third line & 1 \\
Immunotherapy & 1 \\
Second line & \\
Third line & $10(32.3)$ \\
Osimertinib, $\mathrm{n}(\%)$ & $8(80.0)$ \\
Second line & $5(16.1)$ \\
Second line with T790M mutation & $5(100.0)$ \\
Third line & \\
Third line with T790M mutation & \\
\hline
\end{tabular}

Similarly, the high percentage of patients who continue to receive chemotherapy as the only treatment in first line, along with the low use of immunotherapy or latest generation target therapies, implies significant lacunae not only in the awareness of testing but also in working to unlock access barriers that prevent achieving high-quality treatments. Differences in access to healthcare systems and economic barriers generate wide disparities in diagnosis and access to therapy, which are easily visible with real-word data.

\section{Acknowledgements}

The authors would like to thank Dr Swati Krishnan, Dr Kirtika Verma and Dr Ramu Periyasamy (all, Indegene Pvt. Ltd., Bangalore, India) for their support in the medical writing of the current manuscript.

\section{Funding}

The current analysis and manuscript writing were funded by AstraZeneca.

\section{Availability of data and materials}

The datasets used and/or analyzed during the current study are available from the corresponding author on reasonable request.

\section{Authors' contributions}

$\mathrm{CM}$ acquired, analyzed and interpreted the data, and wrote, reviewed and edited the manuscript. $\mathrm{MC}, \mathrm{BO}, \mathrm{RG}, \mathrm{AS}, \mathrm{PH}, \mathrm{SS}$, $\mathrm{BC}, \mathrm{OF}, \mathrm{BS}, \mathrm{GCV}, \mathrm{GA}, \mathrm{KE}, \mathrm{ZM}, \mathrm{CJ}$ and $\mathrm{OE}$ were involved in data acquisition and revised the manuscript. GS contributed to the writing, review and editing of manuscript, as well as study conceptualization. RF wrote the original draft of the manuscript, provided project administration and conceptualized the current study. RF, GCV and CM confirm the authenticity of all the raw data. All authors read and approved the final manuscript.

\section{Ethics approval and consent to participate}

The current study was approved by the Ethics Committee for each site in all the countries that participated, including The Research Ethics Committee of the Alexander Fleming Specialized Medical Institute (CEIAF); IRB Bioethics 
Initiative and Reflection; CIEIS Italian Hospital; Research Ethics Committee Hospital Italian La Plata; CEMIC Research Ethics Committee; Committee of Independent Ethics of the German Hospital; CAICI-CIAP Ethics Committee; Scientific Ethics Committee of the Eastern Metropolitan Health Service; Clinical Scientific Ethics Committee; Santa Maria Clinical Research Ethics Committee of the Clinica del; Country Research Ethics Committee of the San Vicente de Paul Hospital Foundation; Ethics and Research Committee of IMAT Oncomedica S.A; Ethics Committee in Biomedical Research Valle del Lili Foundation; Research Ethics Committee CAIMED S.A.S; Ethics and Research Committee of the National Institute of Cancerology E.S.E; and the Ethics Committee of the Hospital de Clinicas. Written informed consent was acquired from patients when required by local legislation.

\section{Patient consent for publication}

Not applicable.

\section{Competing interests}

Claudio Martin works as Speaker in Roche, MSD, BMS, Boehirenger Ingelheim, Astra Zeneca and AB; MSD, BMS, Roche, Pfzier. Mauricio Cuello declared no conflict of interest and no disclosures to inform. Olga Barajas holds consulting or Advisory role in AstraZeneca; Bristol-Myers Squibb; MSD Oncology; Roche/Genentech and reports research Funding from Bristol-Myers Squibb; MSD Oncology; Sanofi Aventis Travel, Accommodations, Expenses-Roche; Lilly. Gonzalo Recondo, Sandra Aruachan, Herman Perroud and Susana Sena declared no conflict of interest and no disclosures to inform. Carlos Bonilla is in the Advisory board of MSD, Bristol, Eli Lilly, Novartis, AstraZeneca and Speaker in Merck-Serono, Astra-Zeneca, Eli Lilly. Patrocinio de viajes para congresos médicos: Amgen, Merck-erono, Pfizer, MSD, Roche, Tecnofarma, Participación ensayos clínicos: MSD, Roche, BMS y Astra-Zeneca. Francisco Orlandi holds Consulting or Advisory role in AstraZeneca; Bristol-Myers Squibb; Bristol-Myers Squibb; Lilly; MSD Oncology; Pfizer; Roche/Genentech and in Speakers' Bureau of AstraZeneca/MedImmune and reports research funding from Amgen; Astellas Medivation; AstraZeneca/MedImmune; Boehringer Ingelheim; Bristol-Myers Squibb; Celltrion; Genentech/Roche; MSD Oncology. Susana Berutti, Garcia Cocco Virginia, and Alvaro Gomez declared no relationship to disclosure. Ernesto Korbenfeld is doing research in AstraZeneca. Maycos Zapata reports personal fees from Astra Zeneca, Bristol-Myers Squibb, MSD, Roche and non-financial support from Bristol-Myers Squibb, MSD, Roche. Juan Cundom is in the Member Board of MSD Latin America and consulting for Boehringer Ingelheim, MSD and works also as Investigator in clinical trials pharma sponsored; MSD, Eli Lilly. Eric Orellana is employed as Investigator: AstraZeneca, Nektar Therapeutics, Merck Sharp Dohme MSD, Sanofi and Advisory Board and Consultant: AstraZeneca, Roche Genentech and declared no financial conflicts. Susana Goncalves and Florencia Reinhold works for AstraZeneca, Medical Department.

\section{References}

1. Torre LA, Bray F, Siegel RL, Ferlay J, Lortet-Tieulent J and Jemal A: Global cancer statistics, 2012. CA Cancer J Clin 65: 87-108, 2015

2. Bray F, Ferlay J, Soerjomataram I, Siegel RL, Torre LA and Jemal A: Global cancer statistics 2018: GLOBOCAN estimates of incidence and mortality worldwide for 36 cancers in 185 countries. CA Cancer J Clin 68: 394-424, 2018.

3. Smeltzer MP, Wynes MW, Lantuejoul S, Soo R, Ramalingam SS, Varella-Garcia M, Meadows Taylor M, Richeimer K, Wood K, Howell KE, et al: The international association for the study of lung cancer global survey on molecular testing in lung cancer. J Thorac Oncol 15: 1434-1448, 2020.

4. Chen Z, Fillmore CM, Hammerman PS, Kim CF and Wong KK: Non-small-cell lung cancers: A heterogeneous set of diseases. Nat Rev Cancer 14: 535-546, 2014.

5. American Cancer Society: Lung cancer statistics: American Cancer Society available lung cancer statistics: Available at: https://www.cancer.org/cancer/lung-cancer/ about/what-is.html\#: :text=About $\% 2080 \% 25 \% 20$ to $\% 2085 \% 25 \%$ 20of,(outlook)\%20are\%20often\%20similar.

6. Molina JR, Yang P, Cassivi SD, Schild SE and Adjei AA: Non-small cell lung cancer: Epidemiology, risk factors, treatment, and survivorship. Mayo Clin Proc 83: 584-594, 2008.

7. Crinò L, Weder W, van Meerbeeck $J$ and Felip E; ESMO Guidelines Working Group: Early stage and locally advanced (non-metastatic) non-small-cell lung cancer: ESMO clinical practice guidelines for diagnosis, treatment and follow-up. Ann Oncol 21 (Suppl 5): v103-v115, 2010.

8. Economopoulou P and Mountzios G: The emerging treatment landscape of advanced non-small cell lung cancer. Ann Transl Med 6: 138, 2018.

9. Ettinger DS, Wood DE, Aisner DL, Akerley W, Bauman J, Chirieac LR, D'Amico TA, DeCamp MM, Dilling TJ, Dobelbower M, et al: Non-small cell lung cancer, version 5.2017, NCCN clinical practice guidelines in oncology. J Natl Compr Cancer Netw 15: 504-535, 2017.

10. National Lung Screening Trial Research Team, Aberle DR, Adams AM, Berg CD, Black WC, Clapp JD, Fagerstrom RM, Gareen IF, Gatsonis C, Marcus PM and Sicks JD: Reduced lung-cancer mortality with low-dose computed tomographic screening. N Engl J Med 365: 395-409, 2011.

11. Planchard D, Popat S, Kerr K, Novello S, Smit EF, Faivre-Finn C, Mok TS, Reck M, Van Schil PE, Hellmann MD, et al: Metastatic non-small cell lung cancer: ESMO clinical practice guidelines for diagnosis, treatment and follow-up. Ann Oncol 29 (Suppl 4): iv192-iv237, 2018

12. Raez LE, Nogueira A, Santos ES, dos Santos RS, Franceschini J, Ron DA, Block M, Yamaguchi N and Rolfo C: Challenges in lung cancer screening in Latin America. J Glob Oncol 4: 1-10, 2018.

13. Raez LE, Cardona AF, Santos ES, Catoe H, Rolfo C, Lopes G, Barrios C, Mas LA, Vallejos C, Zatarain-Barrón ZL, et al: The burden of lung cancer in Latin-America and challenges in the access to genomic profiling, immunotherapy and targeted treatments. Lung Cancer 119: 7-13, 2018.

14. Hirsch FR, Zaric B, Rabea A, Thongprasert S, Lertprasertsuke N, Dalurzo ML and Varella-Garcia M: Biomarker testing for personalized therapy in lung cancer in low- and middle-income countries. Am Soc Clin Oncol Educ Book 37: 403-408, 2017.

15. Kris MG, Johnson BE, Berry LD, Kwiatkowski DJ, Iafrate AJ, Wistuba II, Varella-Garcia M, Franklin WA, Aronson SL, $\mathrm{Su} \mathrm{PF}$, et al: Using multiplexed assays of oncogenic drivers in lung cancers to select targeted drugs. JAMA 311: 1998, 2014.

16. Arrieta O, Cardona AF, Martín C, Más-López L, Corrales-Rodríguez L, Bramuglia G, Castillo-Fernandez O, Meyerson M,Amieva-Rivera E, Campos-Parra AD, et al: Updated frequency of EGFR and KRAS mutations in nonsmall-cell lung cancer in Latin America: The Latin-American consortium for the investigation of lung cancer (CLICaP). J Thorac Oncol 10: 838-843, 2015.

17. Lindeman NI, Cagle PT, Beasley MB, Chitale DA, Dacic S, Giaccone G, Jenkins RB, Kwiatkowski DJ, Saldivar J, Squire J, et al: Molecular testing guideline for selection of lung cancer patients for EGFR and ALK tyrosine kinase inhibitors: Guideline from the College of American pathologists, international association for the study of lung cancer, and association for molecular pathology. J Thorac Oncol 8: 823-859, 2013. 
18. Chiang AC, Fernandes AW, Pavilack M, Chiang AC, Wu JW, Laliberté F, Duh MS, Chehab N and Subramanian J: EGFR mutation testing and treatment decisions in patients progressing on first- or second-generation epidermal growth factor receptor tyrosine kinase inhibitors. BMC Cancer 20: 356, 2020.

19. Oxnard GR, Arcila ME, Sima CS, Riely GJ, Chmielecki J, Kris MG, Pao W, Ladanyi M and Miller VA: Acquired resistance to EGFR tyrosine kinase inhibitors in EGFR-mutant lung cancer: Distinct natural history of patients with tumors harboring the T790M Mutation. Clin Cancer Res 17: 1616-1622, 2011.

20. Yu HA, Arcila ME, Rekhtman N, Sima CS, Zakowski MF Pao W, Kris MG, Miller VA, Ladanyi M and Riely GJ: Analysis of tumor specimens at the time of acquired resistance to EGFR-TKI therapy in 155 patients with EGFR-mutant lung cancers. Clin Cancer Res 19: 2240-2247, 2013.

21. Soria-Comes T, Palomar-Abril V, Ureste MM, Guerola MT and Maiques ICM: Real-world data of the correlation between EGFR determination by liquid biopsy in non-squamous non-small cell lung cancer (NSCLC) and the EGFR profile in tumor biopsy. Pathol Oncol Res 26: 845-851, 2020.
22. Su PL, Yang SC, Chen YL, Wu YL, Lin CY, Chang WY, Tseng YL, Lai WW, Ho CL, Lin CC and Su WC: Real-world outcomes of NSCLC patients receiving tissue or circulating tumor DNA-guided osimertinib treatment. Cancer Med 8: 5939-5947, 2019.

23. Mhanna L, Guibert N, Milia J and Mazieres J: When to consider immune checkpoint inhibitors in oncogene-driven non-small cell lung cancer? Curr Treat Options Oncol 20: 60, 2019.

This work is licensed under a Creative Commons Attribution-NonCommercial-NoDerivatives 4.0 International (CC BY-NC-ND 4.0) License. 